\title{
Plasma-enhanced chemical vapor deposited silicon oxynitride films for optical waveguide bridges for use in mechanical sensors
}

\author{
Storgaard-Larsen, Torben; Leistiko, Otto
}

Published in:

Journal of The Electrochemical Society

Link to article, DOI:

$10.1149 / 1.1837619$

Publication date:

1997

Document Version

Publisher's PDF, also known as Version of record

Link back to DTU Orbit

Citation (APA):

Storgaard-Larsen, T., \& Leistiko, O. (1997). Plasma-enhanced chemical vapor deposited silicon oxynitride films for optical waveguide bridges for use in mechanical sensors. Journal of The Electrochemical Society, 144(4), 1505-1513. https://doi.org/10.1149/1.1837619

\section{General rights}

Copyright and moral rights for the publications made accessible in the public portal are retained by the authors and/or other copyright owners and it is a condition of accessing publications that users recognise and abide by the legal requirements associated with these rights.

- Users may download and print one copy of any publication from the public portal for the purpose of private study or research.

- You may not further distribute the material or use it for any profit-making activity or commercial gain

- You may freely distribute the URL identifying the publication in the public portal 


\title{
Plasma-Enhanced Chemical Vapor Deposited Silicon Oxynitride Films for Optical Waveguide Bridges for Use in Mechanical Sensors
}

\author{
Torben Storgaard-Larsen \\ Brïel \& Kjaer A/S, DK-2850 Naerum, Denmark \\ Otto Leistiko \\ Microelectronics Centre, Technical University of Denmark, DK-2800 Lyngby, Denmark
}

\begin{abstract}
In this paper the influence of RF power, ammonia flow, annealing temperature, and annealing time on the optical and mechanical properties of plasma-enhanced chemically vapor deposited silicon oxynitride films, is presented. A low refractive index (1.47 to 1.48) film having tensile stress has been developed as cladding material for optical waveguides. By combining this waveguide material with a special type of UV photosensitive glass, a low tensile stress strip-loaded waveguide structure, based on a three-layer sandwich structure, has been designed and the stress distribution through the structure investigated.
\end{abstract}

\section{Introduction}

Silica is of great interest as a material for fabrication of integrated optical circuits. Optical waveguides made of these materials have very low losses and most important have optical and mechanical properties compatible with optical fibers. Also when standard silicon is used as a substrate the path is open for the monolithic integration of optical circuits with microelectronic and micromechanical elements. Silica-on-silicon technology offers the potential of high precision fabrication of compact optoelectromechanical microsystems.

Planar silica-on-silicon waveguide devices can be fabricated by different techniques. The waveguide layers can be formed by thermal oxidation, chemical vapor deposition (CVD) processes such as low pressure (LPCVD), plasma-enhanced (PECVD), and microwave plasma (MPCVD), or a combination of these. Also, flame hydrolysis can be used for high temperature fabrication of high quality optical waveguides. ${ }^{1,2}$ Doping silica, with materials such as nitrogen, fluorine, phosphorous, or germanium, can be used to control precisely the refractive index. Also the mechanical properties can be adjusted by accurately controlling the processing conditions. Confinement of the optical field in the lateral direction of the film layer structures is most often achieved by patterning a part of the structure, either the core layer or the top cladding layer, in order to create a waveguiding effect.

In this work plasma-enhanced chemical vapor deposition (PECVD) has been chosen for deposition of waveguide glasses. PECVD glasses have been shown to possess both excellent optical and mechanical properties..$^{3-6}$ Offering, as it does, the possibility of changing deposition variables such as temperature, pressure, RF-frequency, RF-power, and gas composition, a PECVD reactor is a powerful tool for developing glasses having special properties. By adjusting these parameters, one can alter and optimize film properties. Unfortunately, plasma physics is extremely complex and often the processing variables interact, which makes measuring and interpreting the effect of a specific variable difficult. Furthermore, thorough characterization of the deposited glasses is very time-consuming. A detailed description of plasma physics and plasma chemistry can be found in Ref. 7-9.

This work has focused on developing high quality glasses that can fulfill our special requirements and mapping these into the relevant macroscopic parameters such as refractive index, deposition rate, etch rate, and stress. Suggestions for possible explanations of the measured glass properties are given, knowing full well that further characterization is needed in order to determine the actual material compositions and stoichiometries of the glasses. Comparison of glasses developed in this work with glasses from other groups is difficult, since the glass properties do not only depend on the chosen recipe, but also very strongly on the applied reactor designs.

In this paper process development for fabrication of glass waveguide bridges containing a photosensitive core glass is described. An introduction to the experimental equipment and procedures and a short description of measurements performed for characterizing the glasses prepared, is given in the next section followed by the results of deposition and characterization of PECVD oxynitrides. Finally, fabrication and mechanical characterization of three-layer waveguide structures is presented. Discussion of the development and characterization of the applied core/glass will be presented in a later article.

\section{Experimental}

A load-locked parallel-plate STS (E-type) PECVD reactor was used for deposition of the glasses in this work. The reactor can be driven both by a low frequency $(380 \mathrm{kHz})$ $\mathrm{RF}$-power supply and a high frequency (13.56 MHz) RFpower supply. The reactor contains two parallel 10 in. diam electrodes separated by a distance of $22 \mathrm{~mm}$. The lower electrode, which supports the substrate, is grounded. A schematic of the PECVD reactor is shown in Fig. 1. A more detailed description of the PECVD reactor can be found in the article by Mattsson ${ }^{10}$.

Annealing was carried out in a Tempress furnace at temperatures ranging from 700 to $1100^{\circ} \mathrm{C}$ in a $\mathrm{N}_{2}$ atmosphere. To avoid thermal shocks, slow loading/unloading $(10 \mathrm{~mm} / \mathrm{min})$ was applied and dummy wafers were used in both ends of the quartz furnace boat. Warm up, from the

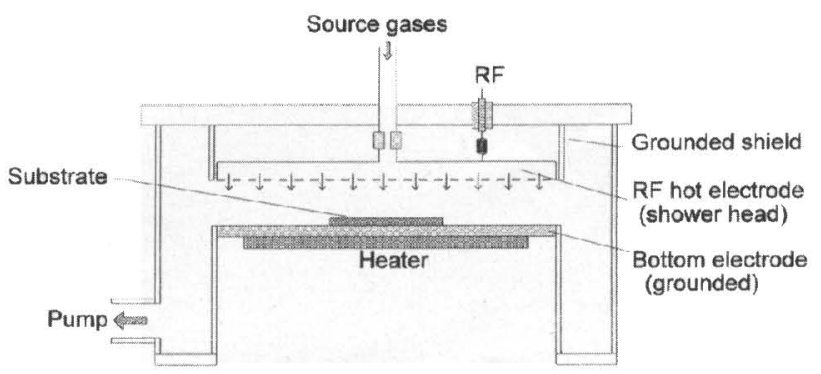

Fig. 1. Schematic diagram of parallel plate PECVD reactor. ${ }^{10}$ 
standby temperature of $700^{\circ} \mathrm{C}$, was done at a speed of $10 \mathrm{~K} / \mathrm{min}$ while cooling was done at $4 \mathrm{~K} / \mathrm{min}$. Also, argon was tested as the ambient atmosphere, but no significant changes in film stresses and refractive indexes were measured when using this more expensive alternative.

The total mechanical stress of the films at room temperature was determined with a Tencor surface profiler by measuring the curvature of the silicon wafer before and after the deposition and after each of the following thermal annealing steps. For stress measurements film thicknesses of more than $2 \mu \mathrm{m}$ were preferred to ensure high accuracy. The reproducibility of the stress measurements were within $\pm 1 \mathrm{MPa}$. Finally, the applied sign convention is positive $(+)$ when tensile stress and $(-)$ when compressive.

The measured stress $\left(\sigma_{1}\right)$ can be written as the sum of the intrinsic stress $\left(\sigma_{i}\right)$ related to deposition kinetics and the thermal stress $\left(\sigma_{t h}\right)$ attributed to difference of thermal expansion coefficients of film and the silicon substrate. The thermal stress component can be expressed by the following simplified equation ${ }^{11}$

$$
\sigma_{\text {th }}=\frac{E^{\prime}}{1-\nu^{\prime}}\left(\alpha_{\mathrm{f}}-\alpha_{\mathrm{Si}}\right)\left(T_{\text {dep }}-T_{\text {meas }}\right)
$$

where $E^{\prime} /\left(1-v^{\prime}\right)$ is the elastic stiffness constant for the film, $\alpha_{\mathrm{f}}$ and $\alpha_{\mathrm{Si}}$ are thermal expansion coefficients of the silicon film and the substrate, $T_{\text {meas }}$ the temperature at which the stress measurement is made, and $T_{\text {dep }}$ the deposition temperature. For thermal oxide layers on a silicon substrate the constants are: $E^{\prime} /\left(1-\nu^{\prime}\right)_{\text {oxide }}=8.5 \times 10^{10} \mathrm{~Pa}$, $\alpha_{\mathrm{f}}=0.55 \cdot 10^{-6} \mathrm{~K}^{-1}$, and $\alpha_{\mathrm{Si}}=2.6 \cdot 10^{-6} \mathrm{~K}^{-1} .^{12}$

The thickness and refractive index were measured with a prism coupler system ${ }^{10}$ capable of measuring the refractive index with an accuracy better than $\pm 2 \times 10^{-4}$ and determining the thickness with an accuracy of $\pm 0.02 \mu \mathrm{m}$. The system which is operated at an optical wavelength of $632.8 \mathrm{~nm}$ is preferably used on glass films having thicknesses exceeding about four wavelengths $(\sim 2 \mu \mathrm{m})$. Each film was measured at the center of the wafer, and in radial distances of 1 and $2.5 \mathrm{~cm}$ from the center. Four inch diameter, 450 to $550 \mu \mathrm{m}$ thickness, single-side polished (100) silicon wafers were used as substrates during development of the PECVD glasses.

\section{Deposition and Characterization of PECVD Oxynitride}

Integrated optical waveguide structures based on a PECVD silicon oxide $\left(\mathrm{SiO}_{2}\right)$ and silicon oxynitride $\left(\mathrm{SiO}_{2} \mathrm{~N}_{y}\right)$ have been shown to possess excellent optical and mechanical properties. ${ }^{3}$ Planar waveguides having optical losses below $0.25 \mathrm{~dB} / \mathrm{cm}$ have been reported, while membrane structures and cantilever microresonators with incorporated optical waveguides have been demonstrated for optical sensing. Carefully adjusting the processing parameters oxynitrides offer a large refractive index range varying from $1.46\left(\mathrm{SiO}_{2}\right)$ to $2.0\left(\mathrm{Si}_{3} \mathrm{~N}_{4}\right)$, which makes this material very suitable as core material in waveguide structures having oxide as the cladding material. While oxide films typically exhibit compressive stress in the range from -200 to $-300 \mathrm{MPa}$, high $\mathrm{RF}$-frequency PECVD nitrides are known for being highly tensile in the range from 400 to $600 \mathrm{MPa}$. Hence, stress control in a large range is another interesting feature of PECVD oxynitrides. In order to ensure good coupling to an optical fiber the refractive index of our waveguides were chosen to be close to the typical indexes of standard singlemode optical fibers, i.e., 1.45 to 1.47 .

Experimental details.-This section describes the work on developing a glass which is believed to offer the optimal compromise between the required optical (low refractive index) and mechanical (zero/low tensile stress) properties.

Nonstoichiometric amorphous silicon oxynitride films $\left(\mathrm{SiO}_{x} \mathrm{~N}_{y}\right.$ ), having high optical and mechanical quality, can be deposited by reacting $\mathrm{SiH}_{4}, \mathrm{~N}_{2} \mathrm{O}$, and $\mathrm{N}_{2}$, and/or $\mathrm{NH}_{3}$ in a plasma. Since PECVD silicon oxynitride films, as- deposited, have been shown to have a hydrogen content exceeding 7 atom percent $(\mathrm{a} / \mathrm{o})^{13} \mathrm{SiO}_{x} \mathrm{~N}_{y} \mathrm{H}_{z}$ might describe the film better than $\mathrm{SiO}_{x} \mathrm{~N}_{y}$.

Feuchter has contributed to the development of process conditions, which could be used for PECVD of high RFfrequency oxides, and oxynitrides suitable for high quality/low loss waveguides. ${ }^{14,15}$ Encouraged by these results, the processing conditions shown in Table I were chosen for developing glasses having the special optical and mechanical properties described above. Compared to the processing conditions of Feuchter ${ }^{15}$ a 500 sccm $2 \%$ silane in nitrogen flow has been replaced with undiluted silane and a separate nitrogen flow. The nitrogen flow is maintained in order to ensure a high gas flow, which is believed to reduce the formation of particles in the deposition chamber and in order to enable correlation of results obtained in this work with results reported in by Feuchter. With the chosen processing conditions the nitrogen flow $\left(\mathrm{N}_{2}\right)$ is not believed to add any significant amount of nitrogen to the films, which could cause an increase of the refractive index of the film.

The work described in this section has mainly been concentrated on investigating the influence of processing power, ammonia flow, and postannealing on the properties of silicon oxynitride based on the process conditions given in Table I. Unless otherwise stated, the thicknesses of the films were about $2 \mu \mathrm{m}$.

Note that since the flows of $\mathrm{SiH}_{4}, \mathrm{~N}_{2}$, and $\mathrm{N}_{2} \mathrm{O}$ are kept constant at a fixed total pressure, the partial pressures of these gases will decrease when adding ammonia to the gas mixture. Since the change of the partial pressures is limited to about $5 \%$ at a maximum ammonia flow of $100 \mathrm{sccm}$, no corrections are made on results that presumably are only slightly influenced by this.

Results and discussion of the deposition experiments.-Annealing Temperatures and Processing Power-The influence of annealing temperature and RF-power on stress and refractive index has been investigated. Figure 2 shows the development of total film stress $v s$. annealing temperature for oxynitrides deposited at five different $\mathrm{RF}$ power levels ranging from 100 to $200 \mathrm{~W}$. The films were deposited with an ammonia flow of $50 \mathrm{sccm}$. The wafers were sequentially annealed $2 \mathrm{~h}$ in a nitrogen atmosphere at each of the temperatures $700,800,900,1000$, and $1100^{\circ} \mathrm{C}$ The results show that annealing can change the total stress from being highly compressive (as-deposited) into tensile, with a maximum stress being observed when the films were annealed at temperatures between 700 and $800^{\circ} \mathrm{C}$ Increasing the temperature further results in the total stress becoming compressive again. At $1100^{\circ} \mathrm{C}$, the stress levels of the films are almost identical to the original asdeposited stress. The curves are seen to have almost the same shape for all five RF-power levels, indicating that the stress vs. annealing temperature behavior is not changed by varying the processing power. The level of stress (intrinsic stress), however, increases when lowering the $\mathrm{RF}$ power.

An estimate of the contribution of thermal stress to the total stress is indicated by a dashed line in Fig. 2. The estimate has been calculated using Eq. 1, assuming that we can use the elastic stiffness constant and thermal expansion coefficients for thermally grown oxide. The dashed line also indicates that the films might possibly develop

Table I. The process conditions used for the deposition of the silicon oxynitride films.

Process variable Process conditions

Flow (sccm)

RF power, W

Pressure, mTorr Temperature, ${ }^{\circ} \mathrm{C}$ 490 1500 0 to 100 75 to 200 800 


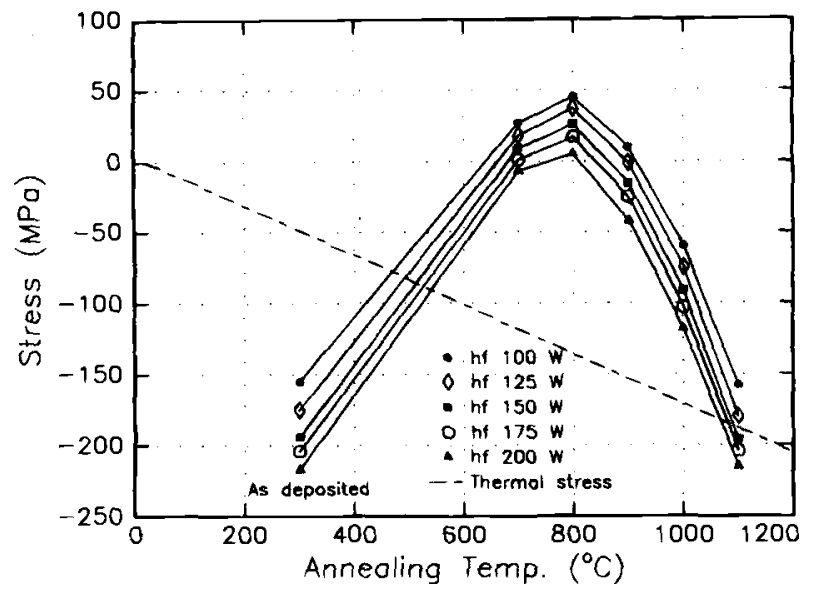

Fig. 2. Variations in total stress with annealing temperature, with the RF-power as parameter. The dashed line is on estimate of the contribution of thermal stress to the total stress, calculated from Eq. 1. (Annealing time: 2 h, No. S24 - S28.)

tensile intrinsic stresses exceeding $200 \mathrm{MPa}$ when being annealed at $800^{\circ} \mathrm{C}$.

A modification of the experiment shown in Fig. 2 was carried out. Six identical oxynitride films processed at an $\mathrm{RF}$ power of $200 \mathrm{~W}$ were annealed. Five wafers were annealed only once at one of the five elevated annealing temperatures used in the experiment of Fig. 2 and the sixth wafer sequentially at all of the five temperatures. The experiment showed that there was no significant difference in the total stress of the films. The stress was only determined by the highest applied annealing temperature and not by heat-treatments which have taken place at lower temperatures. This observation, which is important when planning processing for device fabrication involving sequential heat-treatments, is in agreement with the results on PECVD oxides (oxynitrides) reported by Schliwinski. ${ }^{12}$

The refractive index and the total stresses in the films as functions of the RF power are displayed in the Fig. 3 and 4. Two different ammonia flows of 50 and $100 \mathrm{sccm}$ have been investigated. Both the refractive index and the stress increase with decreasing power and/or increasing ammonia flow. Hence, a compromise has to be found between the refractive index and the total stress of the films. Choosing a RF power of $100 \mathrm{~W}$ seems to satisfy both our demands of moderate tensile stress ( 50 to $80 \mathrm{MPa}$ ) and a refractive index (1.47 to 1.48 ) relatively close to 1.46 (thermal oxide).

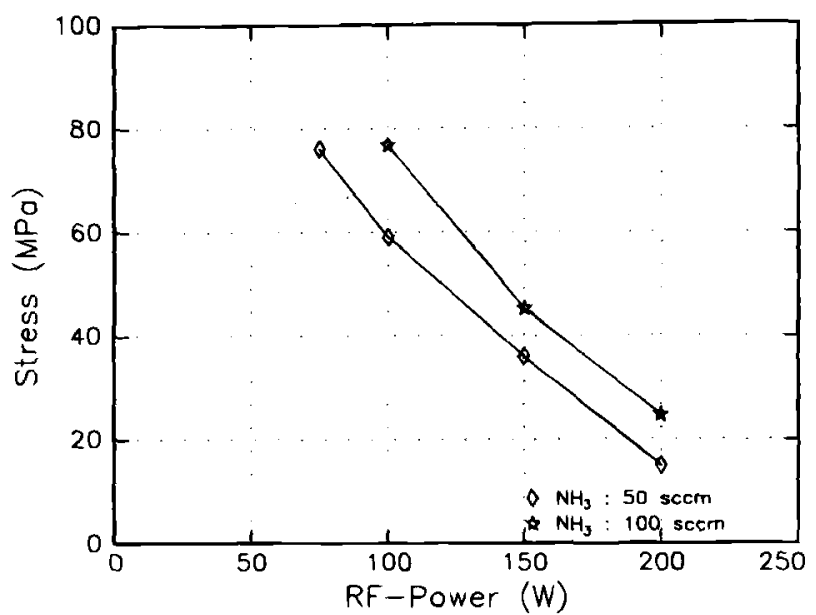

Fig. 4. The total film stress as a function of RF-power at ammonia flow rates of 50 and $100 \mathrm{sccm}$. (Annealing: $2 \mathrm{~h}$ at $800^{\circ} \mathrm{C}$; No. 534 S37, No. S77 - S79.

A more detailed investigation of the influence of the ammonia flow on the glass properties follows.

Figure 5 gives information on the deposition rate of the films described in Fig. 3 and 4. As the RF power decreases from 200 to $75 \mathrm{~W}$ the deposition rate is lowered from about 900 down to $650 \AA / \mathrm{min}$. The deposition rate, however, is considered as being of less importance for our purposes. Finally, a lowering of the power level was observed to cause an increase in the radial uniformity profile of the film on the silicon substrate.

Ammonia flow.-This subsection mainly describes the influence of the ammonia flow upon the properties of oxynitride when processed at a fixed RF power level of $100 \mathrm{~W}$.

Figure 6 shows the refractive index vs. ammonia flow when annealed at 800 and at $1100^{\circ} \mathrm{C}$. The refractive index is seen to be almost linearly dependent on ammonia flow over the range studied. In general, a decrease of the refractive index of about 0.01 was seen when annealing PECVD films at $800^{\circ} \mathrm{C}$. This drop is most likely to be caused by desorption of hydrogen from the film upon annealing. A film having a refractive index of $1.484\left(100 \mathrm{~W}, \mathrm{NH}_{3}: 50\right.$ $\mathrm{sccm}$ ) as-deposited, would have a refractive index of 1.473 after $2 \mathrm{~h}$ of annealing in a nitrogen atmosphere. However, an extra $20 \mathrm{~h}$ of annealing at the same temperature did not seem to have any significant influence on the refractive index.

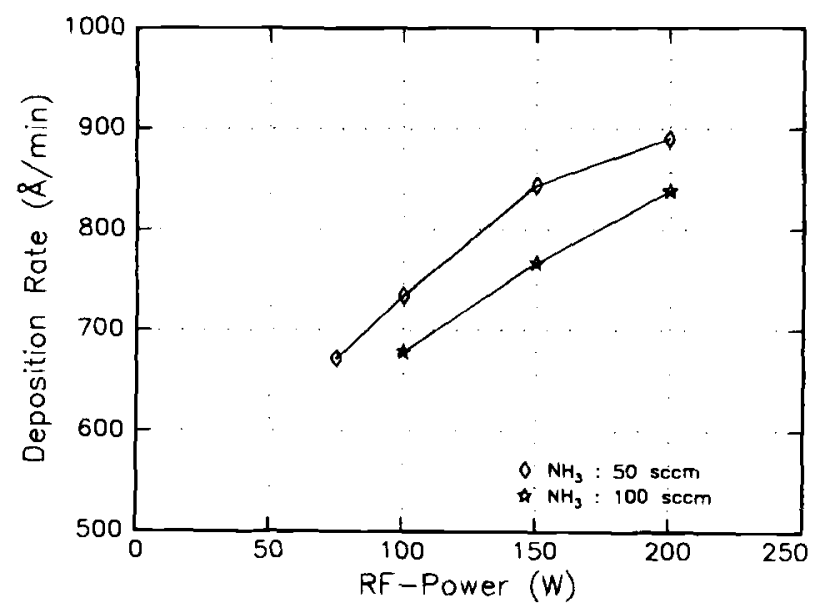

Fig. 5. The deposition rate as a function of RF-power at ammonia flow rates of 50 and $100 \mathrm{secm}$. (Annealing: $2 \mathrm{~h}$ at $800^{\circ} \mathrm{C}$; No. S34 S37, No. 577 - S79.1 


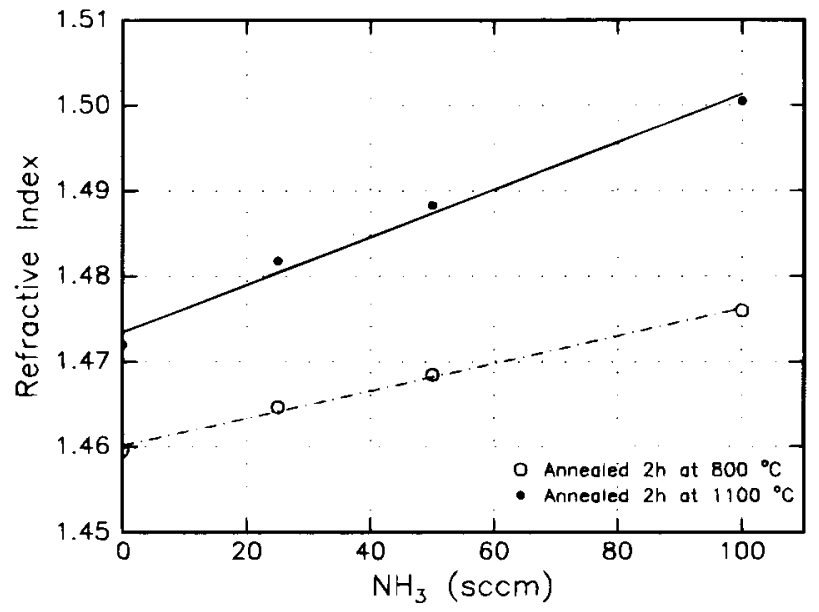

Fig. 6. Refractive index vs. ammonia flow when annealed $2 \mathrm{~h}$ at 800 and $1100^{\circ} \mathrm{C}$, respectively. (RF-power: $100 \mathrm{~W}$, No. S128. S131.)

Figure 6 also shows, that the refractive index increases when being annealed at $1100^{\circ} \mathrm{C}$. This could be due to relaxation processes (densification/rearrangement) in the glass matrix. Also, we observe that nitrogen is probably being incorporated in the films even with a zero ammonia gas flow. A perfect oxide could be expected to have a refractive index of about 1.460 , while this film has a value of about 1.472 . Since the film is certainly not more dense than a thermally grown oxide, we may expect that nitrogen is incorporated in the film. The replacement of oxygen with nitrogen in the glass matrix is known to result in harder, stronger, denser, and chemically more durable films. ${ }^{12}$ Since annealing experiments using either Ar or $\mathrm{N}_{2}$ resulted in glass with the same macroscopic mechanical and optical properties, we conclude that the nitrogen in the glass is originating from $\mathrm{N}_{2} \mathrm{O}$ and/or $\mathrm{N}_{2}$ in the gas mixture. Of course, one could argue that films that were silicon-rich would also have the same properties as described here. We find that this is not likely because of the relatively low refractive indexes and low etch rates observed in these films.

The influence of the ammonia flow upon the total stress of the films is seen in Fig. 7. The total stresses of the asdeposited films and the films annealed at $800^{\circ} \mathrm{C}$ are seen to increase with the nitrogen content. Note that the stress changes from compressive to tensile for $\mathrm{NH}_{3}>0 \mathrm{sccm}$ when the annealing temperature is $800^{\circ} \mathrm{C}$. Finally, the levels of stress at different annealing temperatures (as-

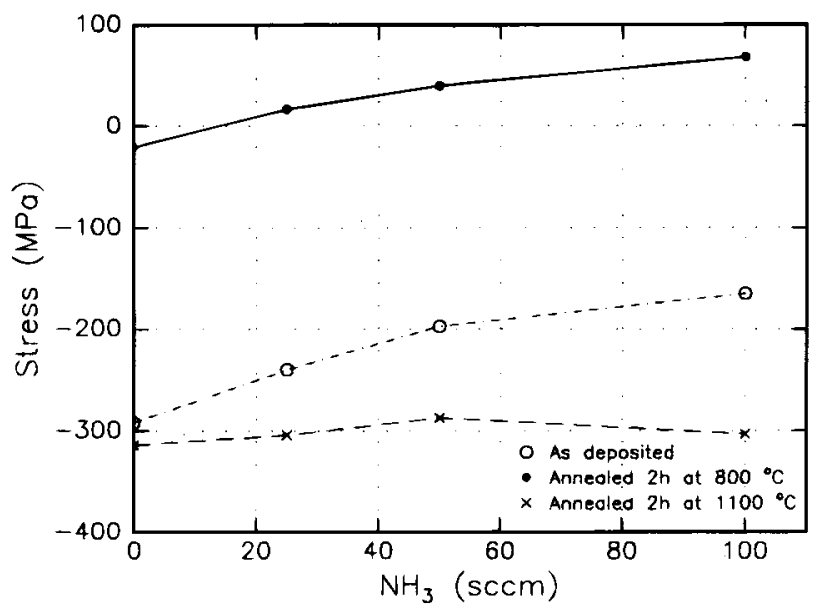

Fig. 7. The total film stress vs. ammonia flow, as-deposited, and after $2 \mathrm{~h}$ of annealing at 800 and $1100^{\circ} \mathrm{C}$, respectively. (RF-power: $100 \mathrm{~W}$; No. S128 - S131.)

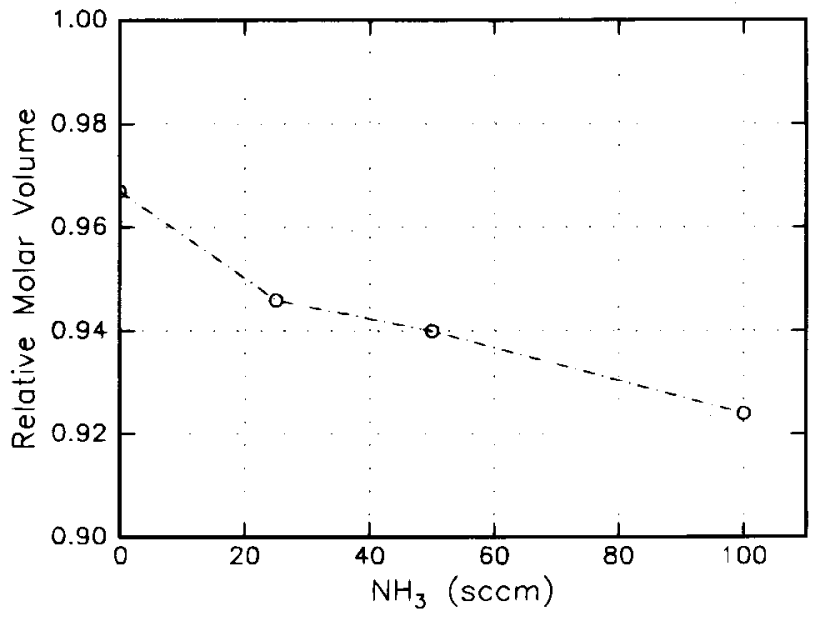

Fig. 8. The relative molar volume change as a function of ammonia flow when annealing the films $2 \mathrm{~h}$ at $1100^{\circ} \mathrm{C}$. The results are relative to the film thickness measured after $2 \mathrm{~h}$ of annealing at $800^{\circ} \mathrm{C}$. (RF-power: $100 \mathrm{~W}$; No. 5128 - \$131.)

deposited, 800 and $1100^{\circ} \mathrm{C}$ ) are in agreement with the experimental results shown in Fig. 2.

Figure 8 shows the change of layer thickness (densification) upon annealing at $1100^{\circ} \mathrm{C}$ for films which have previously been annealed at $800^{\circ} \mathrm{C}$. The change of relative molar volume $V_{\mathrm{m}}$ in terms of the change of layer thickness can be written as $\Delta V_{\mathrm{m}}=1+\left(t_{2}-t_{1}\right) / t_{1} \cdot{ }^{10}$ In our case $t_{2}$ and $t_{1}$ are the film thicknesses after $2 \mathrm{~h}$ of annealing at temperatures of 1100 and $800^{\circ} \mathrm{C}$, respectively. Densification up to about $7 \%$ is seen when the nitrogen content is high. No change in layer thickness was measured upon annealing as-deposited films at $800^{\circ} \mathrm{C}$, which suggests that major densification only occurs at higher temperatures.

Finally, the etch rate in buffered hydrofluoric acid (BHF) is shown in Fig. 9. As-deposited films would typically exhibit etch rates at about $2800 \AA / \mathrm{min}$, which we can interpret as being due to the porosity of the films. When annealed at $800^{\circ} \mathrm{C}$ the etch rate is lowered to a level of about $1200 \AA / \mathrm{min}$. The lowering of the $\mathrm{BHF}$ etch rate here is probably due to cross-linking of $\mathrm{Si}$ and $\mathrm{N}$ upon release of hydrogen from the $\mathrm{Si}-\mathrm{H}$ and $\mathrm{N}-\mathrm{H}$ bonds rather than a densification of the film, which probably needs higher annealing temperatures. The content of nitrogen seems to have no major influence on the BHF etch rate at this level. In contrast, when annealing at $1100^{\circ} \mathrm{C}$ we can observe that the etch rate decreases linearly with the content of ammonia in the gas mixture. This observation gives another

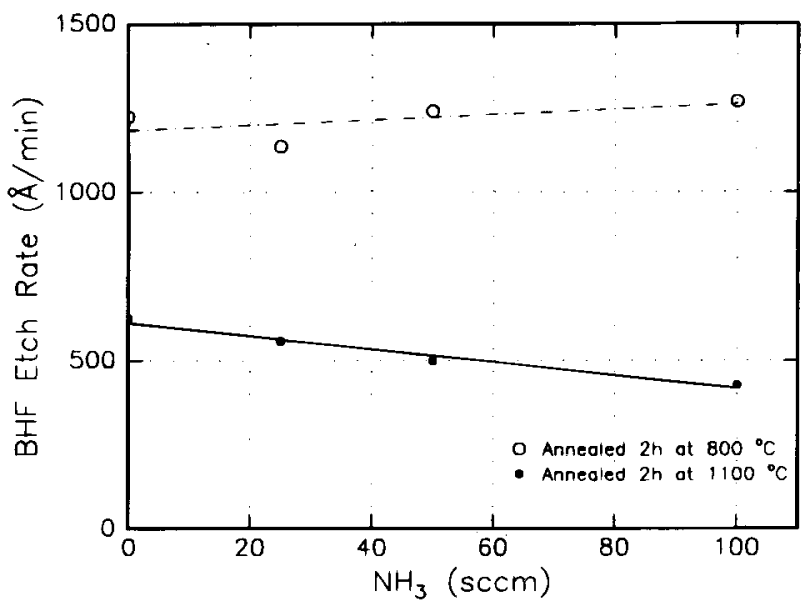

Fig. 9. The BHF etch rate vs. ammonia flow when annealed $2 \mathrm{~h}$ at 800 and $1100^{\circ} \mathrm{C}$, respectively. (RF power: $100 \mathrm{~W}$; No. S128. S131.) 
indication that a densification takes place. The fact that the etch rate, which is $600 \AA / \mathrm{min}$ at zero ammonia flow, is below the etch rate of a thermally grown oxide ( $750 \AA / \mathrm{min})$ gives another piece of evidence that nitrogen originating from $\mathrm{N}_{2} \mathrm{O}$ and/or $\mathrm{N}_{2}$ is incorporated in the film.

Annealing effects.-Figure 10 shows total stress $v s$. annealing time at $800^{\circ} \mathrm{C}$ for varying layer thicknesses for films processed at ammonia gas flows of 50 and $100 \mathrm{sccm}$. The films were sequentially annealed in time steps of 2 to $4 \mathrm{~h}$. As can be seen, the total stress is dependent on both annealing time and layer thickness. Increasing the layer thickness means that a longer annealing time is needed in order to end with a certain total film stress. Accurate tuning of film stresses, obtained by annealing at $800^{\circ} \mathrm{C}$, can be made by reloading the wafers into the furnace followed by further annealing.

Unfortunately, problems with cracking of the glasses were seen in these experiments. The results showed that the chance of getting cracks is related to both layer thickness and the annealing time. At an ammonia flow of $50 \mathrm{sccm}$ a $4.4 \mu \mathrm{m}$ thick layer would show cracking after $14 \mathrm{~h}$ of annealing. A $8.8 \mu \mathrm{m}$ thick layer would show severe cracking, even when the resultant stress of the film layer was compressive at room temperature. An abrupt increase of measured stress was typically seen upon cracking (see Fig. 10), which is an unexpected result in view of the stress relaxation that presumably takes place. However a $13.2 \mu \mathrm{m}$ layer film stays stable (and compressive) after $14 \mathrm{~h}$ of annealing. Presumably the intrinsic stress of this film is still below the critical stress which leads to cracking. After 4 to $8 \mathrm{~h}$ of extra annealing this film would also start cracking. At $\mathrm{NH}_{3}=100 \mathrm{sccm}$ (dashed curves in Fig. 10) no signs of cracking could be seen on 2 and $4 \mu \mathrm{m}$ thick layers after $14 \mathrm{~h}$ of annealing. Other experiments showed that also at this ammonia flow, thicker films $(>8 \mu \mathrm{m})$ could not be brought into a tensile total stress without showing signs of cracking.

Obviously the applied method of achieving tensile stress has the drawback, that during the annealing process at $800^{\circ} \mathrm{C}$, the total stress of the film is being dominated by intrinsic stress which is expected to be highly tensile (see Fig. 2).

In general, the critical film thicknesses and annealing times which lead to cracking, were seen to increase (improve) as the nitrogen content of the films increases. Oxynitride layers having a thickness of about $2 \mu \mathrm{m}$ and a total stress (at $22^{\circ} \mathrm{C}$ ) exceeding $100 \mathrm{MPa}$ (tensile) could actually withstand thermal annealing for more than $24 \mathrm{~h}$ without showing any signs of cracking.

We can conclude that the design compromise, mentioned above, between refractive index and total stress in the film

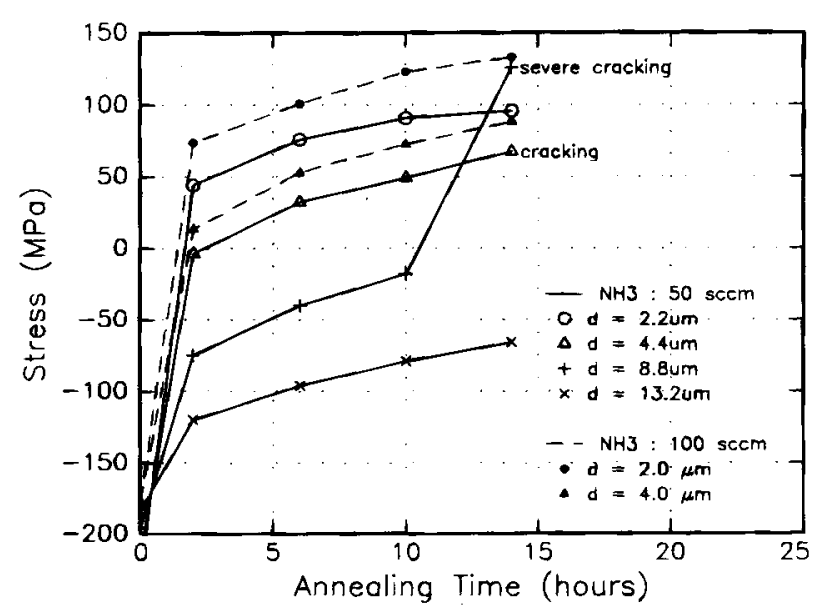

Fig. 10. The total stress as a function of annealing time for various film layer thicknesses. The solid and dashed curves represent ammonia flows of 50 and $100 \mathrm{sccm}$, respectively. (RF power: $100 \mathrm{~W}$; annealing temperature: $800^{\circ} \mathrm{C}$; No. S49 - S52, No. $\$ 97$ - S99.) is also dependent on layer thickness which complicates the designing of optical waveguide bridges even more. It is necessary to reduce the intrinsic tensile stress in order to avoid cracking of films with growing layer thickness. This can be done by increasing the nitrogen content in the film at the cost of a higher refractive index.

The mechanical properties of the films seem to be stable. Even after 2 months at room temperature, no change of stress could be measured on a $2 \mu \mathrm{m}$ thick oxynitride film having a tensile stress of $120 \mathrm{MPa}$.

The stress distribution (gradient) in films having total thicknesses of 5 to $6 \mu \mathrm{m}$ and processed with three different ammonia flows (curve a: 0 sccm, curve b: 50 sccm, curve $c$ : $100 \mathrm{sccm}$ ) was investigated. The results are shown in Fig. 11. To the left of the origin $(\mathrm{d}=0 \mu \mathrm{m})$ we have the silicon/glass interface. The glass/air interface is to the right. After having been annealed $4 \mathrm{~h}$ at $800^{\circ} \mathrm{C}$ to increase the film stress, the total stresses were measured to be -110 , -19 , and $4 \mathrm{MPa}$, respectively, for the three films. Thereafter, the films were sequentially etched back in steps of 0.6 to $0.9 \mu \mathrm{m}$ followed by stress measurements until the surface of the silicon substrate was reached. The average total stresses of the removed layers (thickness 0.6 to $0.9 \mu \mathrm{m}$ ) have been calculated and are given by the symbols plotted in Fig. 11 .

As can be seen the stress distribution is not constant in the thickness direction of the film layer. From having an almost uniform stress distribution in the lower $3 \mu \mathrm{m}$ (0 to $3 \mu \mathrm{m}$ ) of the nitrogen-doped film layers, shown as curves b and $c$, a large (positive) stress gradient is seen for the upper 2 to $3 \mu \mathrm{m}$. Curve c ( $\mathrm{NH}_{3}$ flow: $100 \mathrm{sccm}$ ) shows stress ranging from an average of $-20 \mathrm{MPa}$ at the $\mathrm{SiO}_{x} \mathrm{~N}_{y} / \mathrm{Si}$ interface to about $80 \mathrm{MPa}$ in the upper layer of the film at the glass/air interface.

Curve $d$ which represents a film having processing conditions identical to curve $c$ is deposited in two steps $(3 \mu \mathrm{m}$ $+2 \mu \mathrm{m}$ ) each followed by $2 \mathrm{~h}$ of annealing at $800^{\circ} \mathrm{C}$. After $2 \mathrm{~h}$ of annealing the first step $(3 \mu \mathrm{m})$ exhibited a total stress of 38.4 MPa. After this stress measurement an extra $2 \mu \mathrm{m}$ of the same glass film was deposited followed by another $2 \mathrm{~h}$ of annealing. The total stress of the now $5 \mu \mathrm{m}$ thick oxynitride film was measured to be $1 \mathrm{MPa}$.

Curve d shows that instead of an increase of the attained tensile stress (38.4 MPa), $2 \mathrm{~h}$ of extra annealing after deposition of the $2 \mu \mathrm{m}$ thick top layer, led to a decrease of the average stress of the lower glass layer. During the etchback process the total stress was measured at a glass layer

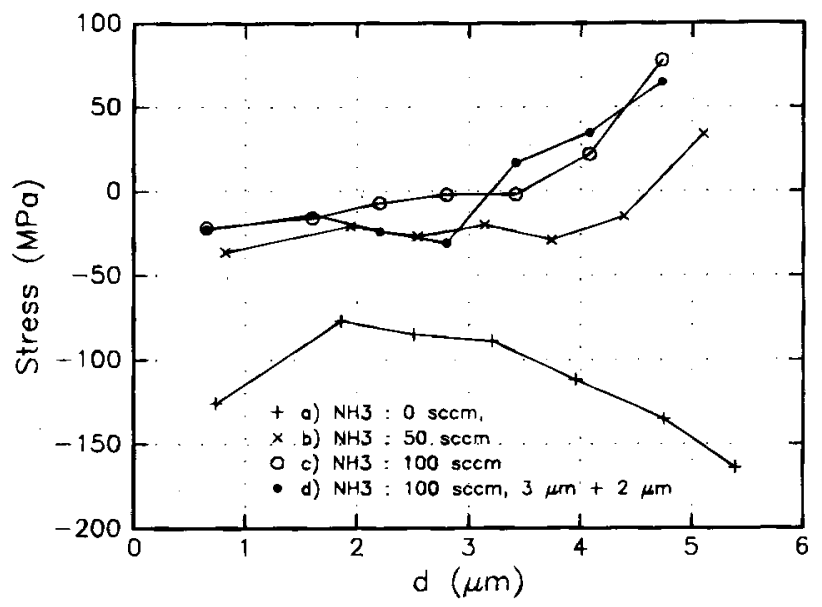

Fig. 11. Depth stress profiles (stress distribution) in film layers with a total thickness of 5 to $6 \mu \mathrm{m}$. The curves represent films processed with ammonia flows of: curve $a: 0 \mathrm{sccm}$, curve b: 50 sccm, and curve c: $100 \mathrm{sccm}$. (Annealing: $4 \mathrm{~h}$ at $800^{\circ} \mathrm{C}$, RF power, $100 \mathrm{~W}$; No. TU26-TU28.) Curve $\mathrm{d}$ represents a film having process conditions similar to curve c. However this film has been deposited in two steps $(3+2 \mu \mathrm{m})$ each followed by $2 \mathrm{~h}$ of annealing at $800^{\circ} \mathrm{C}$. (RF power: $100 \mathrm{~W}$, No. TU32). 
thickness of $3 \mu \mathrm{m}$. Now the stress of this layer was measured to be compressive at $-23 \mathrm{MPa}$. As a result of the deposition of the extra $2 \mu \mathrm{m}$ of glass followed by the extra $2 \mathrm{~h}$ of annealing the average total stress in the lower glass layer had been lowered with more than $60 \mathrm{MPa}$.

This could indicate that diffusion effects rather than rearrangement processes (e.g., densification) play a major role on the intrinsic stresses of oxynitride films when being annealed at $800^{\circ} \mathrm{C}$. The buildup of stress gradients upon annealing of thick oxynitride films (see Fig. 11) can be another explanation for the cracking phenomena described above.

Curve a of Fig. 11 which represents an intended PECVD oxide film ( $\mathrm{NH}_{3}$ flow: 0 sccm), shows a different stress distribution. In contrast to the results shown with curve b, c, and $\mathrm{d}$, the stress is decreasing toward the glass/air interface, suggesting that different annealing effects are dominating. Since the refractive indexes and the as-deposited stresses were identical for films having thicknesses of 2 and $3 \mu \mathrm{m}$, respectively, we conclude that the composition is fairly constant with depth for nonannealed films and that in situ annealing effects during deposition are negligible at $300^{\circ} \mathrm{C}$

The experiment presented in Fig. 12 is a modification of the experiment leading to the results shown in Fig. 2. The $\mathrm{RF}$ power is kept constant at $100 \mathrm{~W}$, but the ammonia flow is varied from 0 to $100 \mathrm{sccm}$. As expected, the stress increases with nitrogen content. It is interesting to note, that the turning point of the stress curve for the PECVD oxide film $\left(\mathrm{NH}_{3}: 0 \mathrm{sccm}\right)$ is below $700^{\circ} \mathrm{C}$, which again is a deviation from the results reported on the films doped with nitrogen by adding ammonia to the gas mixture

In a study of the composition of different PECVD oxynitrides made from a $\mathrm{SiH}_{4}-\mathrm{N}_{2} \mathrm{O}-\mathrm{N}_{2}-\mathrm{NH}_{3}$ gas mixture, both Claassen ${ }^{16}$ and Denisse ${ }^{17}$ conclude that only Si-H, N-H, Si$\mathrm{N}$, and $\mathrm{Si}-\mathrm{O}$ bonds are present in their films. All oxygen is incorporated as $\mathrm{Si}-\mathrm{O}-\mathrm{Si}$ groups which means that $\mathrm{O}-\mathrm{H}$ bonds are absent. However, this could be different for our films since they are deposited using different processing conditions.

Schliwinski et $a .^{12}$ have found that hydrogen release and $\mathrm{Si}-\mathrm{N}$ cross-linking plays a major role in the explanation of properties of annealed silicon oxynitride films. Figure 13 shows the evolution of hydrogen bond concentration as a function of applied annealing temperature for two different oxynitride films. A complete comparison of these films with films prepared in this project is not relevant since different PECVD reactors and processing conditions have been used. Nevertheless, it is seen that the hydrogen appears to be more strongly bonded to nitrogen than to silicon. For oxygen-rich oxynitrides $[\mathrm{O} /(\mathrm{O}+\mathrm{N})>$

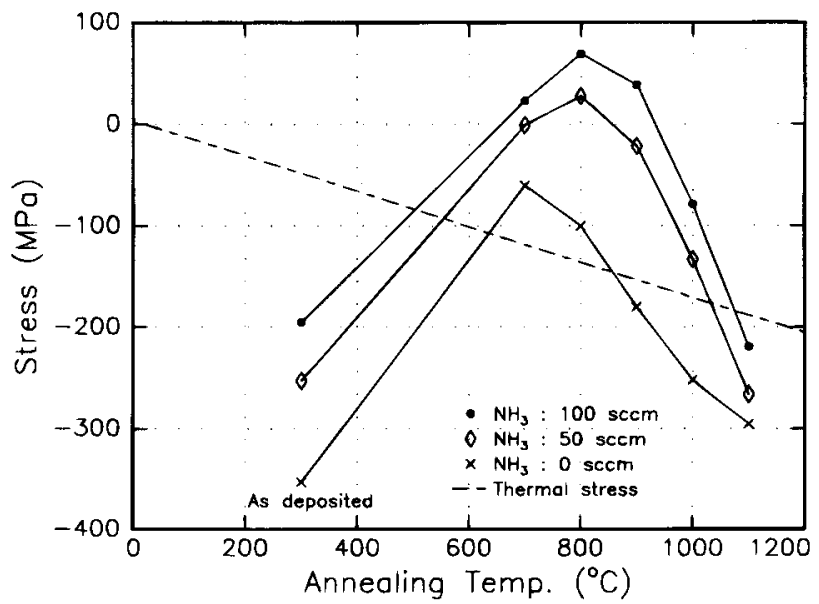

Fig. 12. Variations in total stress with annealing temperature, with the ammonia flow as parameter. (Annealing time: $2 \mathrm{~h}$; No. TU26 - TU28.) The dashed line is an estimate of the contribution of thermal stress to the total stress calculated from Eq.1.
$0.5]$ this is in accordance with experimental results reported from other groups, e.g., Ref. 16.

Figure 13 also shows that almost all Si-H bonds are broken at $800^{\circ} \mathrm{C}$ while only about half of the $\mathrm{N}-\mathrm{H}$ bonds are broken. Apparently the experiments were carried out on $870 \mathrm{~nm}$ thick oxynitride layers, that were sequentially postannealed $30 \mathrm{~min}$ in a nitrogen atmosphere at each of the elevated temperatures indicated in the figure. The desorption of hydrogen starting at annealing temperatures exceeding $400^{\circ} \mathrm{C}$ is presumably followed by cross-linking between $\mathrm{Si}$ and N. ${ }^{16}$ Finally, it is suggested that rearrangement processes causing a decrease of the intrinsic stresses in the films, would start dominating at temperatures higher than $800^{\circ} \mathrm{C}$.

Apparently, our experimental results support the annealing mechanisms suggested by Ref. 12 . Curves b and c in Fig. 11 resemble diffusion profiles, and diffusion of hydrogen from the top layer upon annealing into the bottom layer re-establishing $\mathrm{Si}-\mathrm{H}$ and $\mathrm{N}-\mathrm{H}$ bonds could explain the annealing behavior demonstrated by curve d.

PECVD silicon nitride films generated from the gas mixture $\mathrm{SiH}_{4}-\mathrm{N}_{2}$ in general have a much smaller content of hydrogen than similar films generated from a $\mathrm{SiH}_{4}-\mathrm{NH}_{3}$ gas mixture. ${ }^{16,11}$ The different annealing behavior observed for the PECVD oxide (see curve a in Fig. 11 and 12) could possibly be explained with the absence of ammonia in the gas mixture and, thereby, a smaller content of nitrogenhydrogen bonds although the presence of nitrogen in the film has been demonstrated (Fig. 6 - Fig. 9). Assuming that this will limit the amount of $\mathrm{N}-\mathrm{H}$ bonds that will break during the annealing at $800^{\circ} \mathrm{C}$, we can speculate that the influence upon the stress from the generation of new $\mathrm{Si}-\mathrm{N}$ bonds will be reduced, and that the breaking of $\mathrm{Si}-\mathrm{H}$ bonds will play a major role upon the annealing behavior of the PECVD oxide. With a characterization limited to

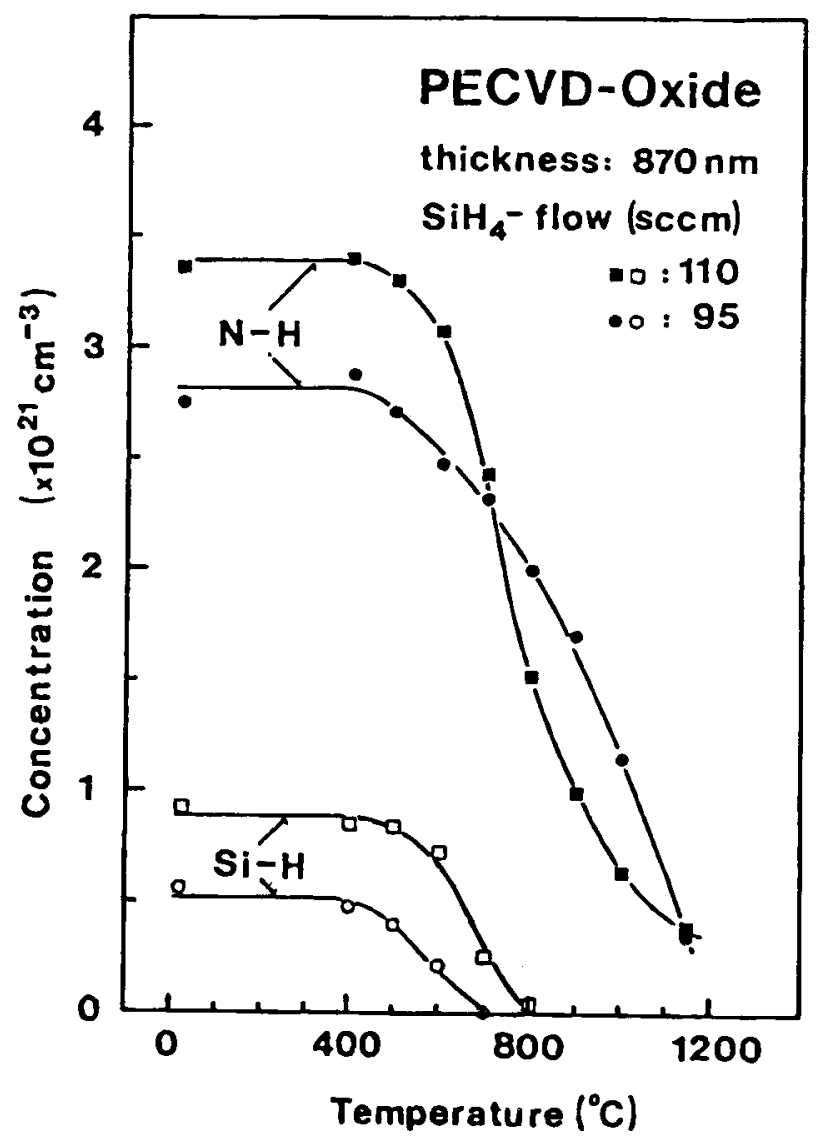

Fig. 13. Evolution of $\mathrm{N}-\mathrm{H}$ and $\mathrm{Si}-\mathrm{H}$ hydrogen bond concentration as a function of increasing temperature for two different PECVD oxide (oxynitride) films. ${ }^{12}$ 
macroscopic properties of the glasses, the fundament for making the above speculations is at best weak.

Additional comments.-The variations in refractive index and thickness across a wafer were within the uncertainty of the prism coupler system. In typical measurements the variations in refractive index was less than $10^{-4}$ and thickness variations less than $1 \%$ (within the uncertainty of the prism coupler system.

Run-to-run reproducibility, of the refractive indexes of the films, was only little affected by the initial conditions of the reactor such as the amount of material deposited onto the electrodes and sidewalls. Even previous deposition of several hundred micrometers of glass of various types, without a physical clean of the deposition chamber, did not seem to have any major influence on the properties of these films. The stress reproducibility of films annealed at $800^{\circ} \mathrm{C}$ was within a few percent as long as no major changes were made to the PECVD system.

The influence on the properties of high RF-frequency PECVD silicon oxynitrides exerted by RF-power, ammonia flow, and annealing temperature, and time has been investigated. The refractive index was seen to increase linearly with ammonia flow. Ammonia flows from 0 to $100 \mathrm{sccm}$ yielded refractive indexes in the range 1.46 to 1.50 . Both the refractive index and the total stress were seen to increase with decreasing RF-power.

By properly choosing processing parameters and postannealing conditions the total stresses of the films could be accurately controlled in the range from $-300 \mathrm{MPa}$ (compressive) to $120 \mathrm{MPa}$ (tensile). The total stress of the film was seen to change from compressive to tensile with annealing temperature reaching a maximum of intrinsic tensile stress between 700 and $800^{\circ} \mathrm{C}$. Above this temperature the total stress would start decreasing until a level, which is close to the thermal stress in a thermally grown oxide, as calculated from a simplified theoretical model. The total stress was shown to increase with time when annealing at $800^{\circ} \mathrm{C}$. Furthermore, it was found that the stress levels obtained upon annealing depended on the thickness of the glass layer. Temperature treatment below the highest applied annealing temperature did not cause significant changes of the total stress.

It is suggested that the increase of total stress upon annealing is related to desorption of hydrogen followed by formation of Si-N cross-linking and that the stress reduction at temperatures above the turning point is due to rearrangement processes (stress relaxation) reducing the intrinsic stress in the film.

Measurements of total stress as a function of measurement temperature is necessary for separating the total stress into contributions from thermal stress and intrinsic stress in order to get a better understanding of the stress/annealing behaviour of the films.

The potential of getting tensile stress in films thicker than 6 to $8 \mu \mathrm{m}$ was distorted by cracking phenomena. After 6 to $10 \mathrm{~h}$ of annealing at $800^{\circ} \mathrm{C}$ they would start cracking.

A film, suitable as cladding material for our waveguide bridges, was found based on what was expected to be the best compromise between refractive index (preferably low), stress (low tensile), and layer thickness. The glass type chosen referred to as SiON100 was processed with an ammonia flow of $100 \mathrm{sccm}$ at an RF power of $100 \mathrm{~W}$ yielding a refractive index of 1.477 and a stress of $38 \mathrm{MPa}$ after $4 \mathrm{~h}$ of annealing of a $5 \mu \mathrm{m}$ thick film at $800^{\circ} \mathrm{C}$.

Measurement of the elemental composition of the glasses using, e.g., Rutherford backscattering (RBS), and information about the chemical structure by means of Fourier transform infrared (FTIR) absorption spectroscopy, would be helpful in order to make a more detailed characterization.

\section{Fabrication of Waveguide Structures}

Small core, high numerical aperture waveguides, normally have limited attraction because of large mode mismatch with standard single mode optical fibers, resulting in high coupling losses. However, in this work the interest was in making waveguide bridges with low tensile stress and small cross section dimensions to achieve a nondistorted frequency response of a waveguide Bragg grating placed in these bridges and a high mechanical sensitivity of the structure. These waveguide bridges, which are $1 \mathrm{~mm}$ long, are employed as stress sensing elements in a silicon optomechanical accelerometer which have been described elsewhere.$^{18}$ The important point here is that the waveguide bridges will experience tension and compression when they are subjected to acceleration along the sensitive axis.

A strip-loaded waveguide structure (see Fig. 14a) was chosen in order to ensure a high mechanical reliability. The presence of the loading strip on the top of the waveguiding core layer, makes the effective refractive index in the region beneath it larger than the effective index in the adjacent regions. ${ }^{19}$ Straight strip-loaded waveguides based on a three-layer cladding/core/cladding structure are relatively easy to fabricate (and have no problems with step coverage). The formation of the loading strip, which laterally confines the light in the three-layer film structure, can be carried out after the high-temperature annealing of the glass. A buried waveguide structure, however, like shown in Fig. 14b, would include step-coverage problems when depositing the PECVD top cladding layer. Also, due to stress concentrations at the edges of the core structure, cracks will occur upon annealing of the top-cladding when applying the glasses discussed in the preceding section.

Stress distribution in a three-layer waveguide structure.-At an optical wavelength of $1.55 \mu \mathrm{m}$ and a total waveguide thickness of maximum 5 to $6 \mu \mathrm{m}$, the relative refractive index difference between the core and cladding layer should be in the order of 0.03 to 0.04 (2 to $2.8 \%$ ) to prevent too high losses due to evanescent field leaking into the silicon substrate. Since the chosen cladding glass (SiON100) has a refractive index of 1.477 , the core glass should preferably have a refractive index in the range 1.51 to 1.52 or higher to ensure a strong field confinement and, thus, prevent too high losses. A schematic diagram illustrating the cross-sectional dimensions and waveguide parameters for a bridge structure is shown in Fig. 15. The dashed rectangle on the figure shows the dimensions of the waveguide glass layers before patterning of the structure by etching. First, a part of the top cladding glass layer is removed by dry-etching for patterning of the strip. Thereafter, the waveguide structure and the substrate are exposed to $\mathrm{KOH}$ wet etching in order to fully release the uniaxial ascelerometer structure mentioned briefly above. A $1 \mu \mathrm{m}$ thick layer of PECVD waveguide glass is sacrificed during the $16 \mathrm{~h}$ of etching in a 27 weight percent (w/o)

a)

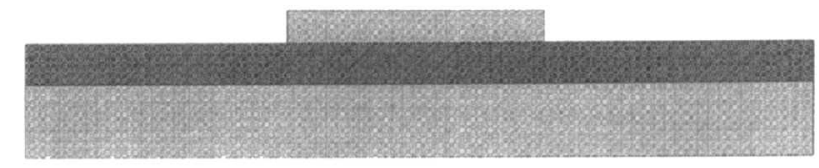

b)

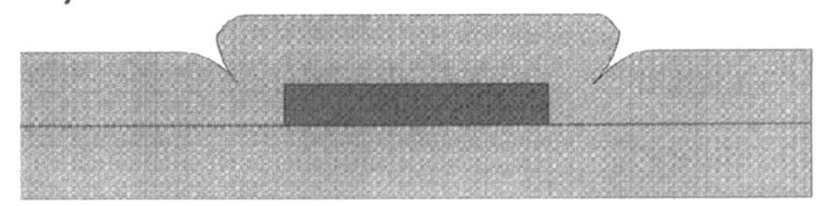

Fig. 14. Schematics of cross sections of (a) a strip-loaded waveguide and (b) a buried waveguide. 


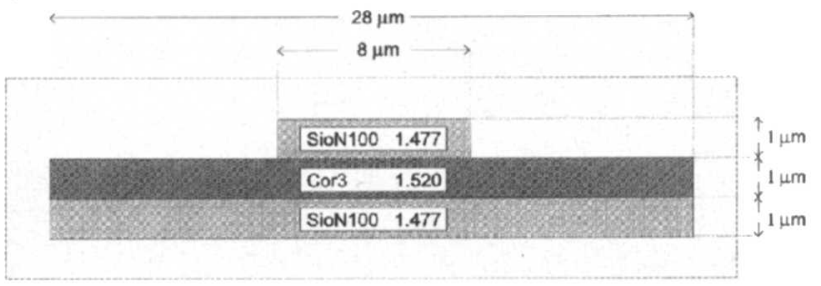

Fig. 15. Schematic showing waveguide geometry and parameters for a bridge structure.

$\mathrm{KOH}$ solution at $60^{\circ} \mathrm{C}$. The part of the waveguide that will be on top of the seismic mass or the frame of the accelerometer structure will only get etched from the top side.

The total stresses in $5 \mu \mathrm{m}$ thick film layers of the special nitrogen-doped germania core glass (Cor 3$)^{20}$ and the cladding glass (SiON100) were measured to be -5 and $+38 \mathrm{MPa}$, respectively, after $4 \mathrm{~h}$ of annealing at $800^{\circ} \mathrm{C}$. By sequentially etching back, as described earlier in the section on Annealing effects, the stresses through the layer thicknesses were investigated. The solid curves in Fig. 16 shows the results obtained on the two glass films. To the left of the origin $(\mathrm{d}=0 \mu \mathrm{m})$ we have the silicon/glass interface. The glass/air interface is to the right. Apparently, the stress gradient at the glass/air interface is less significant for the core glass.

For the fabrication of strip-loaded waveguides a threelayer film waveguide (cladding/core/cladding) glass structure was composed. The glass layer structure consisted of a $1 \mu \mathrm{m}$ thick core layer in a sandwich of two cladding layers each having a thickness of $2 \mu \mathrm{m}$ yielding a total film layer thickness of $5 \mu \mathrm{m}$. The glass structure yielded a total stress of $+38 \mathrm{MPa}$ after $4 \mathrm{~h}$ of annealing at $800^{\circ} \mathrm{C}$ in $\mathrm{N}_{2}$. Measurements of the stress distribution, shown with a dashed curve in Fig. 16, indicated a nonuniform stress distribution yielding tensile stresses in the order of $200 \mathrm{MPa}$ at the core/top-cladding interface. Comparing the curve with the solid curves representing the stress distribution for each of the glass types at similar layer thickness and annealing times, we see that complex stress mechanisms occur when annealing multilayer structures composed by the two glass types.

Large stress gradients in waveguide structures can cause birefringence. The effective refractive index will depend

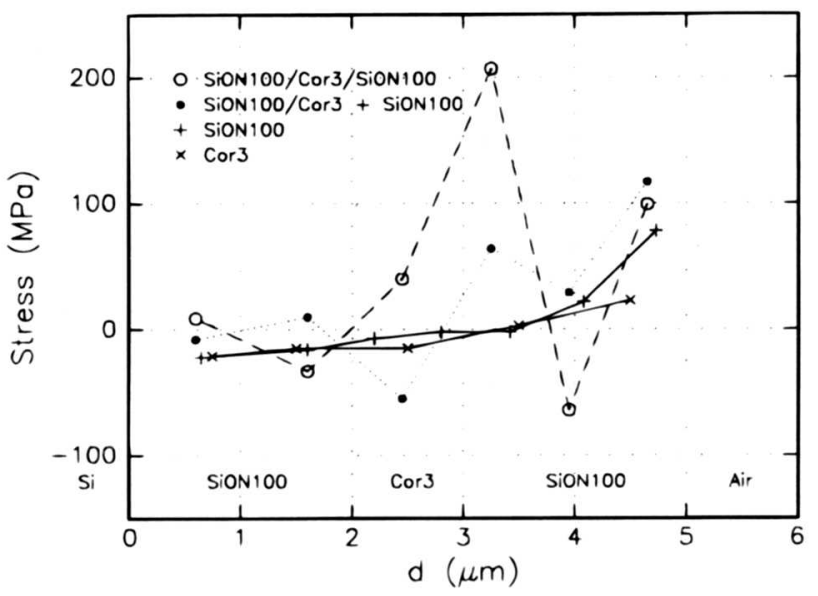

Fig. 16. Depth stress profiles (stress distribution) in $5 \mu \mathrm{m}$ thick films. Solid lines: cladding glass SiON100 and core glass Cor3 (annealing: $4 \mathrm{~h}$ at $800^{\circ} \mathrm{C}$, No. TU26, No. TU29). Dashed curve: three-layer SiON100/Cor3/SiON 100 structure with layer thickness combination of 2/1/2 $\mu \mathrm{m}$; (annealing: $4 \mathrm{~h}$ at $800^{\circ} \mathrm{C}$; No. TU30). Dotted curve: three-layer SiON100/Cor3/SiON100 structure with layer thicknesses combination of $2 / 1 / 2 \mu \mathrm{m}$ deposited in two steps $(3 \mu \mathrm{m}+2 \mu \mathrm{m}$ ) each followed by annealing; (annealing: $2+2 \mathrm{~h}$ at $800^{\circ} \mathrm{C}$; No. TU33). on the state of polarization of light guided in the waveguide structure. Birefringence in the part of our waveguide structure which will contain the Bragg grating can cause a broadening of the filter spectrum unless the light is linearly polarized.

An attempt to reduce the stress gradients in the film was made by dividing the annealing process into two steps of each $2 \mathrm{~h}$. After deposition of the first two layers (lower cladding and the core layer) the film structure was annealed $2 \mathrm{~h}$ at $800^{\circ} \mathrm{C}$ resulting in a total stress of $+39 \mathrm{MPa}$. Hereafter, the top cladding layer was deposited and the complete three-layer structure was annealed $2 \mathrm{~h}$ yielding a total stress of $+19 \mathrm{MPa}$. The result of this modification of the deposition/annealing processes is shown as a dotted line in Fig. 16. It can be seen, that the stress level at the core/top-cladding interface has been lowered. Other combinations of the deposition and annealing steps might lower the stress gradients in the waveguide structure even more.

The high positive stress gradients (toward tensile stress) at the top-cladding/air interface is of less concern, since most of the top-cladding layer is sacrificed during formation of the strip and during the final $\mathrm{KOH}$ etching of the silicon substrate to release the accelerometer structure. As a result of the $\mathrm{KOH}$ etching, edges are rounded improving the mechanical strength of the waveguide bridges.

Formation of surface compressive stresses by postprocessing with a chemical treatment or deposition of a thin layer of, e.g., elastic polymer, might be means of further improving the mechanical strength of the waveguide bridges. However, care shall be taken that these processing steps will not affect the optical properties of the waveguide. Figure 17 shows an SEM picture of the point of attachment of a $1 \mathrm{~mm}$ long waveguide bridge connecting the seismic mass to the frame of a silicon accelerometer structure. ${ }^{18}$ Figure 18 is a close-up view of a waveguide test structure consisting of nine, $4 \mathrm{~mm}$ long, $28 \mu \mathrm{m}$ wide, waveguide bridges suspended in a glass grid. At a wavelength of $1.55 \mu \mathrm{m}$ the strip-loaded waveguides showed single-mode guiding exhibiting minimum propagation losses of $5 \mathrm{~dB} / \mathrm{cm}$ for the TE polarization. The high losses are expected to be due to the thin buffer layer, which cannot prevent propagating light from coupling to the high refractive index silicon substrate.

After testing of the mechanical strength, a numerical simulation should be applied in order to optimize the waveguide configuration for low loss single-mode guiding.

\section{Conclusions}

By adjustment of ammonia flow, RF power, and postannealing temperature and time, it is possible to tune in desirable optical and mechanical properties intermediate between silicon nitride and oxide. By employing high $\mathrm{RF}$ frequency PECVD, silicon oxynitride films exhibiting refractive indexes from 1.46 to 1.50 and total stress rang-

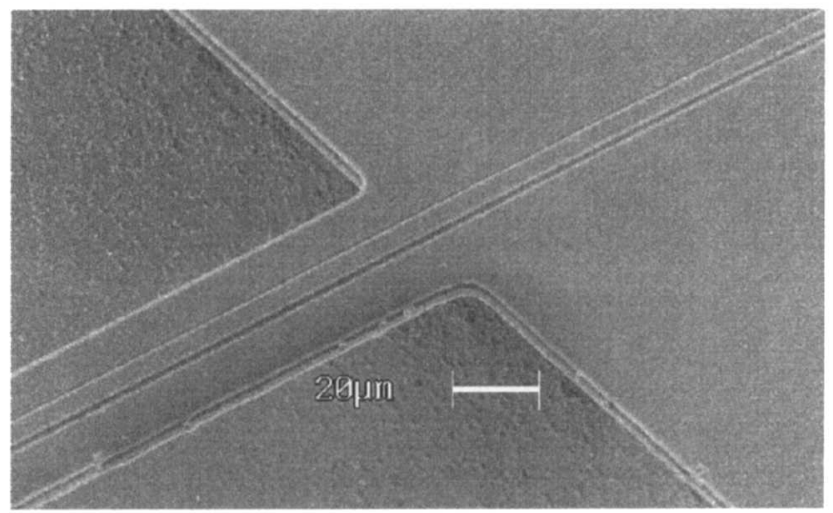

Fig. 17. Close-up view of the point of attachment a $1 \mathrm{~mm}$ long waveguide bridge connecting the seismic mass to the frame of a silicon accelerometer structure. ${ }^{18}$ 


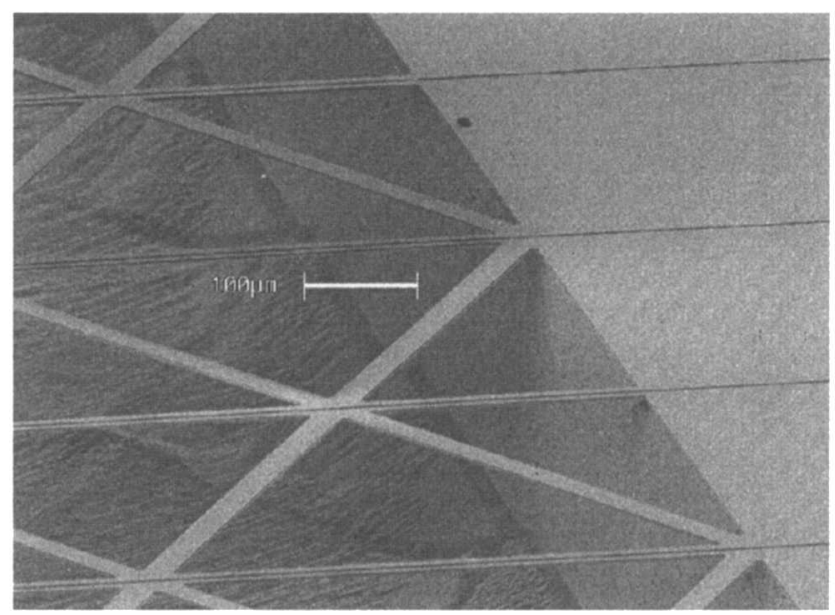

Fig. 18. Close-up view of a waveguide test structure consisting of nine parallel waveguide bridges suspended in glass grid on a silicon substrate.

ing from $-300 \mathrm{MPa}$ (compressive) to $120 \mathrm{MPa}$ (tensile) were fabricated. Maximum tensile stress was achieved by annealing the films at $800^{\circ} \mathrm{C}$ in a nitrogen atmosphere. At this temperature the intrinsic stress was seen to increase with annealing time, and the total stress was found to decrease with increasing layer thickness. Films having thicknesses exceeding $6 \mu \mathrm{m}$ tended to evolve cracking upon annealing.

By properly choosing the processing parameters, a waveguide cladding film offering the "best compromise" between stress (low tensile), refractive index (low, 1.47 to 1.48 ), and film layer thickness (minimum $5 \mu \mathrm{m}$ ) was fabricated.

Process development for fabrication of PECVD glass waveguide bridges exhibiting low tensile stress in the length direction and having a photosensitive core material, has been carried out. Silicon oxynitride and a special photosensitive core glass were chosen as materials for the cladding and the core of the waveguide structure.

A strip-loaded waveguide structure based on the two waveguide glasses mentioned above was designed. This structure is believed to be the best choice to ensure high mechanical strength of a waveguide bridge operating as a strain gauge and, therefore, subjected to both tensile and compressive forces in the length direction of the bridge. The total stress of the waveguide is low tensile to ensure optimum operation of the accelerometer structure. By proper choice of the deposition processes and postannealing processes, stress gradients in the glass are reduced.

\section{Acknowledgments}

We would like to thank Thomas Feuchter (The Microelectronics Centre) for his contribution to development of high frequency PECVD silicon oxynitrides.

Manuscript submitted July 26, 1996; revised manuscript received Dec. 5, 1996.

Brüel and Kjaer A/S assisted in meeting the publication costs of this article.

\section{REFERENCES}

1. T. Kominato, Y. Ohmori, H. Okazaki, and M. Yasu, Electron. Lett., 26, 327 (1990).

2. M. Kawachi and J. Noda, in Proceedings of Optical Fibre Sensors 7 (OFS'7), pp. 101-104 (1990).

3. E. Voges, H. Bezzaoui, and M. Hoffmann, in Proceedings of European Conference on Integrated Optics 1993 (ECIO'93), Neuchâtel, pp. 12.4 - 12.6 (1993)

4. K. Fischer and J. Müller, Sens. Actuators B, 9, 209 (1992).

5. H. Bezzaoui and E. Voges, ibid., 29, 219 (1991).

6. M. Hoffmann, H. Bezzaoui, and E. Voges, ibid., 44, 71 (1994).

7. F. Kaufman, Adv. Chem. Ser., No. 80, p. 29 (1969).

8. F. K. McTaggart, Plasma Chemistry in Electrical Discharges, Elsevier, Amsterdam (1967).

9. Techniques and Applications of Plasma Chemistry, J. R. Hollahan and A. T. Bell, Editors, Wiley (Interscience), New York (1974).

10. K. E. Mattsson, Ph.D. Thesis, Microelectronics Centre, The Technical University of Denmark (1994).

11. W. R. Knolle and J. W. Osenbach, This Journal, 135, 1211 (1988).

12. H.-J. Schliwinski, U. Schnakenberg, W. Windbracke, H. Neff, and P. Lange, ibid., 139, 1730 (1992).

13. Thin Film Processes, J. L. Vossen and W. Kern, Editors, Academic Press, Inc., New York (1978).

14. T. Feuchter, Internal document at the Microelectronics Centre (MIC) (Oct. 1993).

15. T. Feuchter, Internal document at the Microelectronics Centre (MIC) (May 1994)

16. W. A. P. Claassen, H. van der Pol, A. H. Goemans, and A. E. T. Kuiper, This Journal, 133, 1458 (1986).

17. C. M. M. Denisse, K. Z Troost, J. B. Oude Elferink, F Habraken, W. F. van der Weg, and M. Hendriks, $J$. Appl. Phys., 60, 2536 (1986)

18. T. Storgaard-Larsen, S. Bouwstra, and O. Leistiko, Sens. Actuators A, 52, 25 (1996).

19. R. G. Hunsperger, Integrated Optics. Theory and Technology, 3rd ed., Springer Verlag, Heidelberg (1991).

20. T. Storgaard-Larsen, C. V. Poulsen, and O. Leistiko, This Journal, To be published. 